\title{
A IMPORTÂNCIA DAS AGÊNCIAS DE MEDIAÇÃO NO ORDENAMENTO TERRITORIAL DOS ASSENTAMENTOS RURAIS ${ }^{1}$
}

\author{
Claudio Ubiratan Gonçalves*
}

\section{Iniciando os termos da questão}

Os assentamentos rurais também se constituem em espaços importantes de mediação, seja através de "organismos e pessoal do Estado", seja através de entidades de apoio e de representação que tanto podem contribuir para o reconhecimento dos assentados e o seu fortalecimento, como para a desagregação e intensificação das disputas e conflitos internos (MEDEIROS, 1994).

Nota-se ao longo da formação do espaço geográfico brasileiro, principalmente neste último quarto de século, a participação significativa das agências de mediação como sindicatos, partidos políticos e grupos ligados às Igrejas Cristãs no mundo rural. Estas agências envolvem também engajamentos e mobilização de segmentos selecionados para reordenação de modos de conduta e visão social de sua posição (NEVES, 1998).

Sem embargo, queremos pôr em relevo a ação e participação daqueles que aqui consideramos os principais mediadores sociais na luta pela terra, e como eles con-

\footnotetext{
1. O presente trabalho é parte da dissertação de mestrado do autor defendida em 2002. Agradeço as observações críticas dos professores Dr. Ruy Moreira, Dra. Leonilde S. Medeiros e, de forma especial, a minha orientadora Dra. Regina Landim Bruno. Também agradeço a Mônica Cox pela valiosa revisão.

* Doutorando do Programa de Pós-Graduação em Geografia da Universidade Federal Fluminense, Mestre em Desenvolvimento, Agricultura e Sociedade pelo CPDA-UFRRJ.
} 
tribuíram/contribuem com seu saber e técnicas para reduzir a dissonância entre visões de mundo na organização e ações do MST. Interessa-nos, antes de qualquer coisa, saber o sentido de seu surgimento e qual o grau de importância que assumem ao longo do processo de luta pela terra.

Há uma diversidade de entidades que, pela sua ação de solidariedade, abertura de canais de negociação e fornecimento de recursos materiais, poderiam ser classificadas como agências mediadoras. Neste sentido, atemo-nos apenas naquelas que julgamos possuir algum tipo de vínculo mais direto nos.significativos momentos da formação do Movimento dos Trabalhadores Sem Terra ou em seu apoio.

É difícil afirmar com precisão quais entidades e organismos foram os responsáveis diretos pela formação do MST. Porém, tendo como parâmetro que a luta pela terra é um processo histórico inconcluso e, como tal, ocorre em espaços diferenciados, envolvendo múltiplos agentes e atores, destacaremos como recurso de compreensão a ação das CEBs, CPT e Sindicatos Rurais, atribuindo-lhes o papel de mediadores na organização e continuidade da histórica luta pela terra.

Frente a isso, as comunidades eclesiais de base (CEBs), braço da Igreja Católica progressista, surgem em finais de 1960 como um lugar social e espaço de socialização política para os trabalhadores rurais:

Numa sociedade que vivia um periodo de governo autoritário, em que a participação praticamente inexistia e os cidadãos estavam tentando se organizär para lutar pelo direito de ter direito, as CEBs propiciavam um espaço comunicativo (FERNANDES, 1996:73).

Os métodos utilizados pelas comunidades de base (ver, julgar e agir) eram verdadeiras escolas de cidadania, por trazerem o espírito de igualdade e autonomia entre seus participantes. Esta nova concepção de pensar e agir em alguns setores da Igreja contribuiu e mediou a incipiente organização dos trabalhadores. Esse modelo parlamentar flexível, que era a base da organização das CEBs, serviu como referência para as novas formas de organização social que emergiram, como foi o caso do MST: As CEBs eram os lugares onde foi possível criar espaços para se comunicar, aprender e se organizar para lutar, para enfrentar, de fato, o inimigo, para transformar a realidade dura e sofrida (Idem).

Foi no bojo da troca de experiências que a articulação nacional desses movimentos começou a ser construída na tentativa de superar o isolamento. Assim, a Comissão Pastoral da Terra (CPT) também nasceu enraizada em algumas Igrejas Particulares que estavam dando passos para transformar-se a si mesmas, assumindo seu compromisso e participação na luta dos oprimidos, em busca da libertação integral como a única forma de ser Igreja de Jesus Cristo. Não se tratava, então, de criar um novo "movimento de cristãos", mas de ter uma ferramenta, um organismo de serviço que ajudasse a comprometer, de forma mais acertada, a ação da Igreja Católica com a causa dos oprimidos. Esse organismo deveria, por isso, interligar, 
assessorar e dinamizar os que atuavam pastoralmente junto aos camponeses. $\mathrm{Na}$ caminhada, o desejável era que a questão da terra tornasse a ser parte essencial dos planos de ação das igrejas particulares (e de todas as igrejas cristãs, para que todas fossem sinais e testemunho do amor de Deus pela causa dos camponeses). E será "como Igreja", evangelizando, que a Pastoral da Terra prestará serviços aos camponeses. Não como "suplência", mas como serviço (POLETTO, 1985:30). Para Martins (1994):

A CPT tornou ativa a presença da Igreja nas regiões de conflitos sociais, propondose como um canal de expressão e apoio para que os trabalhadores se organizassem especialmente em sindicatos. Por isso, os conflitos sociais por terra dimensionam-se na disputa legal pelo direito de propriedade por parte dos camponeses (MARTINS, 1994:140).

A ação da Pastoral da Terra foi fundamental como agência de mediação na luta pelo acesso a terra, pois encorajou e organizou os trabalhadores que eram (e ainda são) o principal alvo do desemprego causado no campo devido ao impacto da modernização técnica no setor.

Nessa perspectiva, apreciamos o sindicalismo rural, expresso nos confrontos das lutas democráticas de meados dos anos 80 , que origina o novo sindicalismo representado pela CUT. Assim é que os atores que emergiram do novo quadro de confronto não só explicitaram as contradições contidas no processo de valorização do capital e no regime de propriedade existente, como expressaram demandas específicas, em especial a defesa das ocupações de terra que, de certa forma, questionava a prática sindical contaguiana, muito marcada pelo "oficialismo". Além disso, há uma disputa pela representação dos trabalhadores. Os sem terra, juntamente com as oposições sindicais ligadas à Central Única dos Trabalhadores (CUT), polemizaram a hegemonia do "modelo" sindical oficial e, ao acirrar as disputas políticas em torno da estrutura organizativa e das bases representativas, colocavam em xeque o monopólio do sindicalismo na condução das lutas no campo (THOMAZ JR., 1999:3).

Desse modo, temos o esboço dos principais mediadores e aliados que contribuíram na gestação do MST. No transcorrer do tempo de sua formação, eles foram as principais matrizes políticos-culturais que influenciaram o movimento que então emergia.

Logo, é possível compreender como nessa conjuntura histórica de mudanças desiguais e ajustes institucionais de acomodação do novo arranjo produtivo, os trabalhadores rurais passaram a construir um novo espaço de reflexão sustentado no modo de organização social e política (MARTINS, 1996; CALDART, 2000).

Além de outros fatores que foram determinantes na consolidação do MST, queremos ressaltar que a ação de agências mediadoras como: CEBs, CPT e CUT, também se somaram na constituição da identidade sem terra. $\mathrm{O}$ imbricamento de suas 
ações pastorais e sindicais enxertaram na base social dos trabalhadores rurais um trabalho de socialização do saber político.

Este saber político disseminado entre acampamentos e assentamentos, permitiu a organização e a reprodução social do movimento nos distintos momentos históricos de sua formação. Estes momentos são divididos e analisados por Caldart (2000), articulação nacional da luta pela terra, constituição do MST como uma organização social dentro de um movimento de massas, inserção do MST na luta por um projeto popular de desenvolvimento para o Brasil.

\section{Diferentes perspectivas na construção dos assentamentos}

São inúmeros os estudos e análises sobre os assentamentos rurais no Brasil, seus significados, impactos e viabilidade. Leite (1994), por exemplo, alerta sobre as análises dos economistas realizadas nos assentamentos, onde se explicita um viés político claro, de afirmar o sucesso ou fracasso da política de assentamentos e, por consequiência, as possibilidades de uma política de reforma agrária. Esta argumentação vem reforçar a idéia de que o assunto não é pacífico, e, longe de assumir uma corrente de defesa ou bandeira de ataque sobre a viabilidade econômica e política dos assentamentos, pretendemos introduzir mais reflexões ao debate.

Sob o ponto de vista dos movimentos sociais que fazem a luta pela terra, um assentamento é sinônimo de terra conquistada. Do ponto de vista do Estado, o termo indica uma área de terra destinada a um conjunto de famílias sem terra, como forma de solucionar um problema fundiário (CALDART, 2000:26).

A mesma leitura alarga sua interpretação ao afirmar que, trata-se de um processo de transformação que contrapõe o espaço do latifúndio ao espaço das famílias, que passam a viver articuladas entre si. Com isso, é fundamental olhar para o assentamento como um lugar social em movimento que vai sendo produzido através das relações que ali se estabelecem, e das decisões que vão sendo tomadas pelas famílias sem terra (de cada assentamento, mas também do conjunto dos assentamentos, considerando-se o MST) no processo de organizá-lo e de reorganizá-lo permanentemente, a partir das pressões impostas pela realidade (Idem).

Neste sentido, tendo como pano de fundo a sociedade em movimento e o assentamento como lugar social em construção, Zimmermann (1994) analisa seu interior enquanto um espaço de relações sociais onde as características heterogêneas individuais, homogeneizadas no processo de luta pela terra, ressurgem em bases novas. A partir do cotidiano do assentamento, vê-se a criação e recriação de diferentes formas organizativas voltadas para a produção, numa dinâmica rica de situações, impasses e enfrentamentos. A autora, com isso, quer evidenciar os mecanismos sociais internos associativos e dissociativos que interferem na consolidação do projeto de assentamento. Embebida pela fonte teórica de Bourdieu, ela entende que o assentamento se configura num espaço social onde as posições dos atores são 
definidas pelo capital específico que os movimenta, determinando disputas e hierarquias internas. Os agentes sociais travam uma luta concorrencial decorrente de relações de poder existentes em seu interior.

Gonçalves (1999:67) traz importante contribuição à nossa temática, quando estuda o movimento social como categoria geográfica tomando como objeto a territorialidade dos seringueiros no Acre. O autor também dialoga teoricamente com Bourdieu, quando entende a geografia menos como um substantivo e mais como um verbo como o ato/a ação de marcar a terra, de geografar. Assim, as marcas, os limites, as fronteiras são sempre instituídas e, como tais, implicam sujeitos instituintes. Num quadro de mudança social e de reordenamento do poder provocado pelo movimento do seringal na geografia acreana, o atravessador e o patrão do barracão são considerados como mediadores. Trata dos (inter)mediadores, os que vivem na/da travessia, atravessadores que podem ser tanto aqueles dos negócios da economia, como aqueles dos negócios do campo simbólico, como da política, por exemplo.

Nesse contexto, quando uma nova geografia social se engendra mudam, como não poderia deixar de ser, as relações dos lugares entre si e dos espaços entre eles e, assim, mudam as hierarquias, as escalas. É a ordem social que muda. Nessa nova geografia que se engendra no Brasil a partir dos anos cinqüenta, o próprio sentido da territorialidade brasileira estará se redesenhando, posto que novos sujeitos se insinuam instituindo novas territorialidades (Idem).

Ferrante (1994:140), por sua vez, busca perceber as diretrizes políticas dos mediadores e a sua relação com o fazer diferenciado dos assentamentos. Em sua reflexão sinaliza a necessidade de se encarar os assentamentos como processos sociais complicados, cuja constituição, inserida em um complexo e contraditório jogo de forças sociais, reaviva o debate sobre a questão agrária. A autora aponta como risco, que ao estudar essa realidade como processo de resultados certos e unívocos pode implicar uma distorção da complexidade imbricada em sua materialidade concreta; daí a ênfase que se tem dado à necessidade de se trabalhar analiticamente a multidimensionalidade sob uma perspectiva multidisciplinar.

Esta multidimensionalidade da realidade do assentamento pode materializar-se, principalmente, no espaço geográfico e na multiplicidade das relações sociais. Chamamos atenção, que o lugar social do assentado pode ser observado tanto pela geografia como pela sociologia, o que num diálogo conjunto pode oferecer pistas interessantes na investigação da diversidade social do assentamento.

O espaço deve ser considerado como um conjunto indissociável de que participam, de um lado, certo arranjo de objetos geográficos, objetos naturais e objetos sociais, e, de outro, a vida que os preenche e os anima, ou seja, a sociedade em movimento (Santos, 1994:70).

Em certa forma, é com base nessa concepção mais geral de espaço, que Fernandes (1996) opera com a noção de territorialização como processo de con- 
quista da terra. Cada assentamento conquistado é uma fração do território que passa a ser trabalhado pelos Sem Terra. O assentamento é um território dos SemTerra. A luta pela terra leva a territorialização porque ao conquistar um assentamento, abrem-se as perspectivas para a conquista de um novo assentamento. Se cada assentamento é uma fração do território conquistado, esse conjunto de conquistas, chamamos de territorialização.

A tese do autor é sustentada pelo que ele chama de processo de espacialização e territorialização da luta pela terra. Estes processos são explicados pelo multidimensionamento do espaço de socialização política que abrange o espaço comunicativo, o interativo e o espaço de luta e resistência.

O espaço comunicativo é o lugar do conhecer e do aprender. É também o lugar estratégico de formação da cidadania. Essa experiência é construída na vida cotidiana com atividades no seio das relações sociais. Por sua vez a referência para entender o espaço interativo é o processo de construção da práxis. Este espaço é fundamental na construção do conhecimento, na formação dos sujeitos, e no avanço da organização do movimento social. O espaço de luta e resistência é a manifestação pública dos sujeitos e de seus objetivos é, pois, resultado de um projeto de luta dos trabalhadores rurais sem terra, de sua sobrevivência como sujeito histórico.

Ao considerar estas três dimensões do espaço de socialização política do Movimento Sem Terra, temos claro que o espaço social abriga um campo de ação política que contribuirá na formação da identidade coletiva do movimento. É nesse espaço que ocorrerão as atividades sócio-políticas de convivência e enfrentamento, que geram um aprendizado onde os envolvidos são sujeitos de sua própria luta.

Desse modo, a espacialização é compreendida como a reprodução das experiências construídas a partir do espaço de socialização política, em vários e diferentes lugares onde a luta teve início. A espacialização é o movimento dos sujeitos, carregando suas experiências por diferentes lugares do território. É a busca do recomeço como novos sujeitos, o que permite um constante re-fazer-se na sua formação. É a possibilidade da recriação das dimensões do espaço social e do próprio movimento (FERNANDES, 1996: 236).

Após o processo de conquista da terra, os assentados enfrentam um universo de escassez que comprometem a sua própria reprodução como assentados e a reprodução do seu espaço de morada e de trabalho. O fato de o Estado reconhecer legalmente as lutas dos Sem Terra implantando os assentamentos rurais, não é de todo vitorioso, na medida em que a etapa mais difícil ainda está por acontecer. O trabalhador assentado, após um crédito agrícola inicial, tem sido abandonado ao universo de escassez que ronda os assentamentos em sua fase de implantação, sendo desafiado a permanecer na terra sem nenhum tipo de recurso especial, visto que sua condição também é especial. 


\section{Considerações sobre a organização da luta no espaço agrário fluminense}

Quando deslocamos nosso olhar para o meio rural fluminense a partir da década de cinqüenta, constatamos uma série de equívocos nas políticas implementadas pelo poder público, no setor agrícola. A paisagem rural denuncia, através dos parcos investimentos destinados à agricultura familiar, a grande heterogeneidade de formas da produção desarticuladas entre si, com estratégias de política não implementadas em sua totalidade. Políticas inconclusas que mudam com a mudança de governo, e conduzem ao agravamento dos desequilíbrios regionais.

Aliado a estes fatores, assistimos a uma urbanização concentrada e a uma expansão do fenômeno da metropolização (SANTOS, 1993) no Brasil com graves repercussões no Rio de Janeiro. Primeiramente, numa perspectiva histórica, o impacto se fez visível na região da Baixada Fluminense ${ }^{2}$, com o enorme crescimento populacional e sua transformação sucessiva num pólo de especulação imobiliária, devido à proximidade com a capital carioca. Um segundo fator, foi à alteração nas prioridades econômicas de investimentos do governo estadual e federal, favorecendo o turismo em detrimento das atividades agrícolas.

Este descaso para com a população rural e a crescente expulsão dos posseiros, tornou a região palco de violentos conflitos agrários entre os anos de 50 e 60 (GRYNSZPAN, 1987; MEDEIROS, 1989; ALENTEJANO, 1997). A principal força política da época era o partido comunista que revigorava e apoiava a luta camponesa na resistência aos despejos por meio da permanência na terra, manifestações nas cidades e apelos às autoridades. Em meio a isso, nasce no Estado do Rio de Janeiro, a Falerj, que, juntamente com as Associações de Lavradores constituir-se-ão nas principais responsáveis por diversas ocupações de terra no período.

No início dos anos 60, as ocupações ganharam um caráter mais sistemático, tendo a Federação das Associações de Lavradores do Rio de Janeiro (Falerj) à Frente: A Falerj $e$ as associações de lavradores encarregavam-se de espalhar a notícia das ocupações e de juntar as pessoas. A divulgação podia ser feita em reuniões daquelas organizações, encarregando-se os próprios associados da difusão ou em praça pública. As praças e estações, de ônibus ou de trens, pareciam ser locais privilegiados para a arregimentação, principalmente no período em que as ocupações ainda não eram reconhecidas como tal (GRYNSZPAN, 1987:172).

Os conflitos desdobrados no espaço agrário fluminense que reivindicavam desapropriações de terra ocorreram de forma geral, entre posseiros e grileiros. Os lavradores passaram a mobilizar-se construindo um espaço de socialização políti-

\footnotetext{
2. Um programa de drenagem realizado nos anos 40 visava transformar esta região, inicialmente, em uma área de cinturão verde para abastecer a cidade do Rio de Janeiro.
} 
ca através da articulação entre as associações, e a partir do enfrentamento na luta pela terra.

No final dos anos 70 e inicio dos 80 , os conflitos permanecem e novas áreas sofrem com a intensificação da violência no campo. O novo arranjo espacial coloca em tela as regiões da Baía da Ilha Grande e dos Lagos como palco dos acontecimentos de disputas por terra. Dentre os principais fatores destacam-se, os empreendimentos imobiliários e turísticos, e a construção da rodovia Rio-Santos (ALENTEJANO, 1997).

No seio da questão agrária fluminense nasce o $\mathrm{NAF}^{3}$ e surge a $\mathrm{CPT}^{4}$, mediadores da luta, que começam a organizar de modo mais sistemático as ocupações dos lavradores nas terras de trabalho.

Nesse período modifica-se o perfil dos personagens demandantes da terra, é na ocupação de Campo Alegre que se reacendem os conflitos na Baixada. Essa ocupação indica a composição do público preponderante em grande parte das situações futuras: trabalhadores com experiência urbana que, em uma oportunidade de retorno às áreas rurais, buscam-na, não com a intenção de recriar um "modo camponês" de vida, mas de alcançar alternativas de sobrevivência mais estáveis, conjugando o trabalho agrícola com outras atividades ou rendas, dado que muitos deles eram aposentados (MEDEIROS et al, 1999:137).

Com a questão da terra crescendo de importância, neste período de reabertura democrática, algumas questões chamam nossa atenção. Ocorre uma disputa no âmbito da mediação da luta pela terra, para assumir o papel da representação política dos movimentos de ocupação e nos assentamentos.

O primeiro governo Brizola foi marcado pela agilidade política nas negociações com as lideranças dos sem terra, desmobilizando e desarticulando a possibilidade de uma organização sócio-política. A retirada do MST/RJ (NOVICKI, 1994; MEDEIROS et al, 1999), não assumindo o papel de direção política dos movimentos de ocupação e nos assentamentos, criou condições para que não só os técnicos do Estado, mas também, e principalmente, os assessores da CPT-RJ ocupassem esse espaço.

Segundo Medeiros et al (1999:142), é somente no fim da primeira metade dos anos noventa que a luta pela reforma agrária no Rio de Janeiro recuperou forças, embora ainda esteja muito distante da intensidade que teve no início dos anos oitenta. Dentre os motivos destacam-se: as inúmeras dificuldades enfrentadas para a produção e comercialização, e as notícias de sucesso de alguns assentamentos administrados pelo MST, sobretudo no sul do país e região do Pontal do Paranapanema.

\footnotetext{
3. Núcleo Agrícola Fluminense, fundado na Baixada Fluminense com apoio da Igreja, por lideranças camponesas do pré-64, em oposição à entidade sindical de Duque de Caxias.

4. Comissão Pastoral da Terra, órgão da Igreja Católica ligado à CNBB.
} 
Este quadro, associado à reestruturação do setor sucroalcoleiro no Norte Fluminense com quebras e falências de inúmeras usinas, abriu janelas para a volta desse movimento ao Rio, que trouxe a prática da interiorização das ocupações de terras.

Outro impasse, menos de natureza histórica e mais de interesse político, que atua agravando desequilíbrios regionais é a existência de uma diversidade desarticulada presente no meio rural do agro-fluminense (CARNEIRO et al, 1998:8). Esta diversidade agrícola desarticulada em escala regional, remete a uma falta de política pública global que considere todo o território fluminense e sua dinâmica integradora no espaço geográfico. Abarcando toda heterogeneidade das formas de produção é possível assim, romper com esta diversidade desarticulada que impede o desenvolvimento e agrava os conflitos agrários.

A falta de uma perspectiva da totalidade da produção do espaço agrário fluminense acarreta uma visão fragmentada e distorcida da realidade. As consequiências podem ser percebidas pelos inúmeros projetos públicos que foram interrompidos em seu processo e não chegaram a ser concluído. Se as instâncias do Poder Público (Governo Federal, Estadual e Municipal) agissem integradas, e considerassem as formas de organização da produção e dos agroecossistemas existentes, poderia se eliminar o "cemitério" de projetos isolados, abandonados.

O interesse do MST pelo Rio de Janeiro se deve à importância/influência geoestratégica do estado no cenário político nacional como caixa de ressonância a nível nacional dos acontecimentos políticos através da mídia ${ }^{5}$. Outro ponto a se considerar, foi o aumento dos desempregados da cana na região Norte Fluminense. No início dos anos noventa, a "plantation" canavieira provocou um processo de (re)ordenação do espaço agrário (MACIEL, 1999:91), devido à política de centralização industrial pelos mais eficientes e expropriação daqueles usineiros ineficientes (NEVES, 1997:41).

Assim, tornaram-se inevitáveis os conflitos fundiários e as lutas para conquistar frações do território agroaçucareiro fluminense. Dessa maneira, a territorialização do MST no Rio, coincide com a fragmentação do poder usineiro, e com a recusa do assalariado da cana de permanecer no lugar social de subordinação e dominação.

As ocupações nas terras das usinas e o aumento no número de assentamentos na região nos últimos dez anos, apontam para uma alternativa à reprodução social não só aos assalariados da cana, mas também aos demais trabalhadores urbanos das periferias de Campos e Macaé, principais cidades da região norte. Os protagonistas da luta pela terra encontram no Movimento Sem Terra uma nova identidade com base na vivência da pedagogia da luta social.

\footnotetext{
5. No Rio de Janeiro estão concentradas as maiores empresas do país ligadas ao setor de comunicação social (jornal, televisão, revista, etc). E a partir disso irradia-se pelo Brasil uma onda de informação gerada pelos meios de comunicação fluminense.
} 
Neste sentido, o Movimento é constituído pela luta, e, ao mesmo tempo, a conforma. E isto é tanto mais forte, do ponto de vista da formação humana, por se tratar de uma luta social de vida ou morte, de vida inteira. Ser Sem Terra que dizer estar permanentemente em luta para transformar 'o atual estado de coisas'. Ou seja, a luta está na base da formação dos sem-terra, e é a vivência dela que constitui o próprio ser do MST, trazendo presente a própria possibilidade da vida em movimento, onde o que hoje é de um jeito, amanhã já pode ser diferente, ou até já estar mesmo de ponta-cabeça (CALDART, 2000:72).

A vivência do Ser sem terra que desencadeia na construção da identidade do MST é originada na luta e na terra que se conquista com luta. O assentamento é a terra que não se fica devendo a ninguém, é o direito construído na luta.

Portanto, a região Norte Fluminense abre-se como possibilidade de territorialização do MST a partir da interiorização de suas ocupações. As mudanças que vem ocorrendo no ordenamento do território estão relacionadas com a introdução de uma nova visão da apropriação da terra, e com o novo discurso e novas práticas do movimento social que ali instaura uma nova ordem de significação de valores. Não obstante, esta nova configuração espacial só está se fazendo, graças às renovações técnicas operada na base de produção do setor usineiro, e às disputas estabelecidas em seu interior na definição de uma nova hierarquia do poder.

\section{Reordenação técnica e o novo modelado do território}

Bernardes (1995:239) retrata as mudanças desencadeadas no parque industrial do complexo açucareiro fluminense o nível qualitativo aplicado no Norte Fluminense, em um parque açucareiro com mais de cem anos, com toda uma estrutura montada muito antiga, limitou-se a reformas nas usinas, já que os equipamentos eram caros e a região pouco capitalizada. Em geral, não se comprava um "pacote tecnológico", sendo a maior preocupação a produção de maiores quantidades de produto.

Um quadro de mudanças técnicas pode ser observado quando se considera a escala regional analisando-se os atores que dominaram ou que foram absorvidos pelo processo de modernização seletiva da agroindústria açucareira.

Para entendermos as mudanças técnicas mais recentes, operadas no interior do sistema canavieiro do Norte Fluminense, é preciso levar em conta que as transformações por meio da técnica no setor da economia, também transformaram significativamente as feições geográficas do lugar. Assim, o processo de concentração e centralização da produção, no ramo agroindustrial fluminense, vem ilustrar bem os impactos que o setor vem sofrendo.

De acordo com Bernardes (1995:245), um dos ramos agroindustriais onde mais se concentraram as inversões no Brasil nos anos 70 foi o setor sucro-alcooleiro, principalmente a partir do "programa Nacional do Álcool"(1975). Portanto, é nesse 
setor onde mais se podem produzir os efeitos de ordem espacial. O distinto nível de aplicação da tecnologia existente disponível nos anos 70 , tanto quantitativo como qualitativo, aprofundou as diferenças existentes entre as regiões produtoras.

Chamam atenção os aspectos diferenciadores do impacto do uso da técnica sobre o território, estabelecendo parâmetros de desenvolvimento. Neste sentido, o espaço geográfico é condição geral de produção, onde as técnicas significam a renovação na base industrial, e as relações sociais constituem condição geral de produção do território e da renovação da base técnica da produção.

A mesma autora compara o parque Agroaçucareiro de São Paulo com o do Rio de Janeiro e conclui que em São Paulo uma maior racionalidade está presente, os objetos estão mais próximos uns dos outros com relação à articulação, estando tão coesos que formam um sistema local. Cada unidade produtora é uma unidade de investigação, e o saber que ali existe confere um maior movimento ao uso desses objetos, configurando uma nova dinâmica diferencial do espaço. Na região Norte Fluminense acontece o contrário, onde uma maior irracionalidade está presente. Os objetos, embora apresentando uma maior proximidade espacial, estão efetivamente pouco conectados socialmente, e a precária articulação impede que formem um sistema, já que o saber existente em cada unidade confere pouco movimento ao uso dos objetos técnicos, resultando em escasso dinamismo desse espaço (BERNARDES, 1995:247).

No Norte Fluminense, as usinas renovam-se tecnicamente de modo parcial, a produção de cana não corresponde em quantidade e qualidade; são introduzidos alguns quadros técnicos, mas as relações são arcaicas; consegue-se um certo acordo político para a renovação, porém de forma subalterna.

Neste sentido, o espaço paulista por acumular mais tecnologia e informação constitui o espaço do "mandar" e, onde existe menos, é o espaço do "fazer", o Norte Fluminense. No espaço do mandar está presente o motor acionador da racionalidade, enquanto que no espaço do fazer também existe um motor de racionalidade, porém é movido. É precisamente o motor acionador que estabelece a nova divisão regional do trabalho.

Desse modo, entendemos que o Estado foi peça chave no novo ordenamento da técnica no território da cana. O implante técnico no Norte Fluminense, associado ao aumento da capacidade ociosa e à concessão de subsídios por parte do Estado, revela a ambigüidade do papel do Estado na acumulação, significando que pode impor um elevado patamar de irracionalidade às produções, impedindo dessa forma que uma parte substancial dos ganhos ocorra no processo de produção.

Por isso, o Estado foi um dos atores de maior peso, envolvido neste jogo de poder e principal financiador do desenvolvimento desigual na região canavieira de Campos dos Goytacazes, através de fartos subsídios. Nos anos setenta tornou-se um acumulador de condições do processo de produção.

Ao considerarmos as benesses do Estado destinado aos usineiros, notamos que, foram criados institutos de pesquisa. Estimulou-se o desenvolvimento de inova- 
ções tecnológicas, estabeleceram-se condições especiais de importação e facilidades para concessão de crédito com taxas de juros subvencionadas.

O Estado, principal condutor das mudanças técnicas, também desenvolveu mecanismos de atração e de estabilização de mão-de-obra, ora facilitando a tecnificação no campo e substituindo atividades, ora estimulando a fixação desses excedentes nas cidades de tamanho médio. Assim, procurou absorver contradições e conflitos sociais, principalmente os que estavam imediatamente presentes nas relações sociais de produção, intervindo nas atividades sindicais.

Em função de necessidades da produção capitalista definida a nível mundial, a região em questão herdou dos anos setenta, a modernização conservadora do território. Tendo em vista adequar o espaço, de modo a assegurar a transferência geográfica do valor a nível internacional, como conseqüência direta do desenvolvimento capitalista desigual.

Bernardes (1995:260) nos informa que à medida que regiões como o Norte Fluminense não possuíam determinadas condições de acumulação, devido ao exercício anterior da própria forma de produzir, o Estado financiaria e seria o agente modernizador em muitos espaços concretos. Uma modernização que, no fundo, foi portadora de uma irracionalidade, efetuando processos incompletos, que afetaram concretamente a qualidade das relações sociais de produção.

Num primeiro momento, o processo de adequação ao novo padrão técnico exigiu a destruição de algumas formas anteriores de produção que impediam as condições gerais de produção atual, centralizando o capital. O processo de fusão, que antecedeu o de concentração do capital, implicou uma nova coligação de interesses entre usineiros, que passou a agregar novos proprietários, alguns procedentes de outras regiões, em particular do Nordeste, com maior acesso às esferas políticas no âmbito federal (ANDRADE, 1994; BERNARDES, 1995).

Nos anos cinquienta a região não era considerada um subespaço tradicional, no sentido de qualificar-se como pouco dinâmico. Esse espaço transformou-se em tradicional, simultaneamente ao florescimento da nova região industrial de São Paulo, no marco de uma nova divisão regional do trabalho no Brasil.

Entretanto, após os anos 70, apesar da entrada de capitais externos no Norte Fluminense, principalmente proveniente do Nordeste, e de mudanças também muito positivas na sua estrutura produtiva, toda essa modernização não foi suficiente para evitar que a área se tornasse estagnada, transformando-se no que se poderia denominar uma área tradicional.

Esse momento afigura-se com uma lacuna no âmbito de um escasso nível de competição capitalista. Foram dadas as condições para que se criasse no Norte Fluminense a questão regional, no sentido de decidir sobre o uso do território para instituir um papel para si, frente às mudanças que se verificavam no país, com vistas à participação aos novos projetos do setor.

Neste sentido, a questão regional no Norte Fluminense se vinculava, portanto, às transformações na estrutura produtiva e dizia respeito à disputa daquele espaço, 
ou seja, à mudança daquela forma de produzir, significando o acesso às instâncias políticas e tecnocráticas do período. Demonstra, assim, a necessidade daquelas frações oligárquicas históricas, agora ampliadas com novos grupos, com certa influência política, de estabelecer para si um papel, uma função, frente ao projeto mais amplo de país que se instituía naquele período. É desse modo, que a busca da auto-suficiência levou os usineiros a desenvolverem múltiplos mecanismos de destruição de parte do sistema produtivo anterior.

Tais fatos revelam que o rompimento político no pacto de classes, que passa pela questão regional, não estava colocada somente no interior do estrato usineiro, já que a produção de cana também foi alcançada pela produtividade da usina. Quando se tem em conta às condições gerais em sua globalidade, nas quais se inscrevem as novas técnicas, se percebe que as demais frações proprietárias também foram atingidas pelo pacto. De modo que a indústria foi determinante somente até certo ponto, já que não possuía um domínio pleno sobre o território, não conseguindo alcançar uma adequação técnica perfeita, necessitando subordinar-se, por exemplo, para obter a matéria-prima (BERNARDES, 1995; NEVES, 1997).

Em conseqüência, as novas necessidades de matéria-prima conduziram à reorganização do território, uma vez que era necessário estabelecer adequação na propriedade da terra, no processo de produção agrícola e nas relações de produção, significando que uma parte do esquema anterior foi excluída, outra parte subordinada e uma terceira integrada, a partir de novas alianças (BERNARDES, 1995:267) ${ }^{6}$. Dito de outro modo, a fusão e a concentração do capital implicou na exclusão das usinas ineficientes, subordinação dos pequenos e médios produtores às novas técnicas agrícolas e adequação daquelas com maior barganha política e disponibilidade de capital.

As transferências de valor entre as frações capitalistas permitem perceber qual é a fração proprietária que efetivamente determina o esquema. $\mathrm{O}$ fato dos usineiros passarem a transferir lucros para os grandes e médios produtores de cana indica que, nesse momento, a fração usineira ficou mais fragilizada.

Dependendo do lugar em que os objetos criados para permitir a produção econômica sejam colocados, a resposta à relações mais amplas que se desejam impor será distinta, ou seja, a mesma técnica obtém respostas diferentes em cada lugar porque o uso dos objetos não é igual. A introdução de uma mesma técnica apresenta, portanto, relações distintas em cada subespaço, influenciada pelo conjunto dos fatores concretos. Daí a relevância de exaltarmos as peculiaridades e diferenças do setor sucroalcooleiro paulista frente ao fluminense.

Nesse contexto, temos não só um novo padrão técnico no sistema canavieiro, mas também a construção de uma nova ordem social. Esta nova ordem social gesta-se a partir da territorialidade sem terra que pode ser compreendida, quando tomamos como análise o espaço social do acampamento ou assentamento, como

${ }^{6}$ Grifo nosso. 
uma realidade produzida pelas relações sociais entre as classes e o lugar social. No lugar social desenvolvem-se as experiências que constroem o Movimento em questão. Esse processo cria e recria a possibilidade da conquista de fração do território: a terra (MARTIN, 1997:27).

Das cinco ocupações realizadas até dezembro de 1997 no estado do Rio de Janeiro, quatro delas localizaram-se no Norte Fluminense e envolveram ex-trabalhadores de usinas canavieiras falidas, e duas deram-se nas próprias terras destas usinas (MEDEIROS et al, 1999:145). Neste aspecto, a tecnificação do território traz junto de si o reaparecimento do conflito agrário, que tem sua origem em parte, na desterritorialização da mão-de-obra rural. Esta mão-de-obra excedente é empurrada para a cidade, e transformada em trabalhadores assalariados da cana. Dentre os assalariados da cana, desterritorializados, emana a organização para resistir, lutando e ocupando terras.

Por outro lado, quando consideramos a organização dos trabalhadores, a união, é fator preponderante, conforme salienta Gonçalves (1999:67), quando estudou a territorialidade seringueira. Implica numa comunidade territorial que vá além do espaço vivido, pressupondo-o; que vá além do lugar/dos lugares, contendo-os. A expressão e prática do sentimento de união, invocado na conformação de identidades coletivas é o ingrediente agregador mais utilizado, que vem contar positivamente na territorialização dos sem terra no Rio de Janeiro.

O conflito se constitui, assim, como um momento privilegiado dessa conformação de identidades, de configuração de "comunidades de destino". É quando cada um começa a perceber que o seu destino individual está num outro com/contra o qual tem que se ligar/se contrapor (GONÇALVES, 1999:85).

A conformação da identidade sem terra é forjada neste processo contraditório de territorialização do capital e desterritorialização da mão de obra, e vice-versa, numa reação de um à ação do outro.

A eliminação do colonato e morador de fazenda e/ou a sua transformação em bóias-frias, provocou a liberação de áreas de subsistência para a cultura da cana. A extensão dos direitos e da legislação trabalhista ao campo foi o estopim que iniciou significativas mudanças na região resultando na quebra do esquema de dominação/subordinação anterior. Além da destruição desses cultivos e relações de produção, outros tipos de cultivos e atividades, que impediam a expansão da cana, também foram eliminados no processo de adequação do espaço às necessidades da nova forma de produzir.

\section{Considerações finais}

Nos conflitos de terra, os acontecimentos que marcaram as disputas no campo da política serviram para demonstrar as fragilidades institucionais dos mediadores e do próprio Estado no processo de regularização fundiária. Por outro lado, sem a 
presença e atuação dos mediadores nos espaços decisórios do processo de negociação da reforma agrária os caminhos teriam sido ainda mais conflituosos.

No nosso entendimento, as ações dos assentados e dos mediadores dão sentido e significação a forma que se torna forma-conteúdo espacial. Portanto, o assentamento visto como forma-conteúdo assume um papel ativo no movimento do todo social. O todo social por sua vez resulta da interação dialética da forma espacial sobre o conteúdo social e vice-versa.

O assentamento é um processo histórico de transição e transformação, de organização do território, do espaço agrário em questão. No assentamento o lugar e a relação social se processam enquanto fonte de poder e resistência. Como vimos anteriormente, integrados ou excluídos do sistema econômico competitivo, os trabalhadores constroem estratégias que garantam a materialização e reprodução de sua existência.

Neste aspecto, as conclusões aqui apresentadas são, em nosso pensamento, uma pequena contribuição para o debate acerca da reforma agrária, incorporando novas abordagens como a mediação política no uso e ordenamento do território. Acreditamos ser este, um assunto polêmico e minado de questões que ainda não foram totalmente esclarecidas no meio acadêmico e para o conjunto da sociedade e dos movimentos sócio-territoriais.

\section{A IMPORTÂNCIA DAS AGÊNCIAS DE MEDIAÇÃO}

\section{NO ORDENAMENTO TERRITORIAL DOS ASSENTAMENTOS RURAIS}

Resumo: É na perspectiva política de construção dos assentamentos rurais do espaço brasileiro que, nesse texto, nos debruçamos. Mais precisamente, nos dedicamos a discutir de que forma e como os atores políticos organizam sua luta na prática de mediação das negociações no ambiente de conflito agrário. Aborda ainda as disputas institucionais que se travam a partir da ocupação da terra e a configuração territorial resultante desse processo. Focaliza também a dinâmica e expressão geográfica dos novos arranjos técnicos das usinas agroaçucareiras com significativo apoio do Estado.

Palavras-Chave: Mediação política - Ordenamento territorial - Assentamento rural Movimento Sem Terra - Espaço agrário fluminense.

\section{THE IMPORTANCE OF MEDIATION AGENCIES IN TERRITORIAL ORDERING OF RURAL SETTLEMENTS}

Abstract: This text is focused on the political perspective of rural settlements construction of the Brazilian space. We discusse specifically the forms and processes by which political actors organize their struggles in the mediation practice of agrarian conflicts negotiations. We deal with the institutional disputes from land occupation and territorial configuration that result from this process. We focus on the dynamic and geographic expression of new technical arrangements of sugarcane industry with significant state support.

Keywords: Political Mediation - Territorial ordering - Rural settlements - Landless movement - Fluminense agrarian space. 


\section{BIBLIOGRAFIA}

ALENTEJANO, P. R. R. (1997) Reforma agrária e pluriatividade no Rio de Janeiro: repensando a dicotomia rural-urbano nos assentamentos rurais. Dissertação de Mestrado. Rio de Janeiro: CPDA/UFRRJ.

ANDRADE, M.C de. (1994) Modernização e Pobreza: A expansão da agroindústria canavieira e seu impacto ecológico e social. São Paulo: UNESP.

BERNARDES, Julia Adão. (1995) Mudança técnica e espaço: uma proposta de investigação, in Geografia: Conceitos e temas. CASTRO, Iná Elias et al. (orgs.). Rio de Janeiro: Bertrand Editora.

BRUNO, Regina. (1997) Senhores da Terra, Senhores da Guerra. Rio de Janeiro: Forense/Edur.

(2002) O ovo da serpente. Tese de doutorado. Campinas: Unicamp.

CALDART, R. Salete. (2000) Pedagogia do movimento Sem Terra: escola é mais do que escola. Petrópolis: Vozes.

CARNEIRO, Maria José et al. (1998) Campo aberto, o rural no Estado do Rio de Janeiro. Rio de Janeiro: Contra Capa Livraria.

FERNANDES, Bernardo Mançano. (1996) MST: Formação e Territorialização. São Paulo: Hucitec.

FERRANTE, Vera Lúcia B. (1994) Diretrizes Políticas dos mediadores: reflexões de pesquisas, in Assentamentos Rurais: uma visão multidisciplinar. MEDEIROS, Leonilde (Org.). São Paulo: UNESP.

GONÇALVES, Cláudio U. (2002) A Mediação Política e o ordenamento do território. Dissertação de Mestrado. Rio de Janeiro: CPDA/UFRRJ.

GONÇALVES, C. W. P. (1999) A territorialidade seringueira. In.: Geographia, revista do Programa de Pós-Graduação em Geografia da UFF, no. 2, ano 1, Niterói: UFF.

GRYNSZPAN, Mário. (1987) Mobilização camponesa e competição política no estado do Rio de Janeiro (1950-1964). Dissertação de Mestrado. Rio de Janeiro: PPGAS/UFRJ.

LEITE, S. P. (1994) Por uma economia política da reforma agrária: custo de implantação e infra-estrutura nos assentamentos rurais paulistas (1984-1989), in Assentamentos Rurais: uma visão multidisciplinar. MEDEIROS, Leonilde (Org.). São Paulo: UNESP.

MACIEL, Caio A.A. (1999) Norte Fluminense, um espaço agrário em mudança: o caso do município de Conceição de Macabu. In.: Revista de Geografia, UFPE/DCG-NAPA, no.1, v.15, Recife: UFPE.

MARTIN, Jean-Yves. (1997) A geograficidade dos movimentos socioespaciais. In.: Caderno Prudentino de Geografia, no. 19/20, Presidente Prudente: UNESP.

MARTINS, José de Souza. (1994) O poder do atraso - ensaios de sociologia da história lenta. São Paulo: Hucitec. 
(1996) Revisando a questão agrária. In.: Jornal Sem Terra, $\mathrm{n}^{\circ}$ 160, São Paulo: MST.

MEDEIROS et al, Leonilde S. de. (1999) Luta por terra e assentamentos rurais no estado do Rio de Janeiro, in A formação dos Assentamentos Rurais no Brasil. MEDEIROS, Leonilde (Org.). Porto Alegre/Rio de Janeiro: Ed. Universidade/UFRGS/CPDA.

MEDEIROS, Leonilde S. de. (1989) História dos movimentos sociais no campo. Rio de Janeiro: Fase.

NEVES, Delma P. (1997) Assentamento rural: reforma agrária em migalhas. Niterói: Eduff.

. (1998) O desenvolvimento de uma outra agricultura: o papel dos mediadores sociais, in Para Pensar Outra Agricultura. FERREIRA, A. D. Damasceno (Orgs.). Curitiba: EDUFPR.

NOVICKI, V. (1994) Governo Brizola, movimentos de ocupação de terras e assentamentos rurais no Rio de Janeiro (1983-1987), in Assentamentos Rurais: uma visão multidisciplinar. MEDEIROS, Leonilde; et al. São Paulo: UNESP.

POLETTO, Ivo. (1985) A CPT, a Igreja e os Camponeses. in Conquistar a terra, reconstruir a vida: CPT- dez anos de caminhada. CASALDÁLIGA, Pedro (Org.). Petrópolis: Vozes.

SANTOS, Milton. (1993) A urbanização brasileira. São Paulo: Hucitec. . (1994) Metamorfoses do espaço habitado. São Paulo: Hucitec. (1997) Espaço e Método. São Paulo: Nobel.

THOMAS JÚNIOR, Antonio. (1999) O sindicalismo rural no Brasil, no rastro dos antecedentes. In: Revista Paranaense de Geografia, no. 2, v. 2, Curitiba: AGB.

ZIMMERMANN, Neusa de Castro. (1994) Os desafios da organização interna de um assentamento rural. In: Medeiros, L. et al. Assentamentos Rurais: uma visão multidisciplinar. São Paulo: UNESP. 